\title{
Tolerancia de la imprecisión en el estado de necesidad*
}

\author{
Tolerability of imprecision under necessity defense
}

Rodrigo Andrés Guerra Espinosa'

Fecha correspondencia:

Recibido: 23 de octubre de 2019.

Revisión: 5 de marzo de 2020.

Aceptado: 20 de marzo de 2020.

\section{Forma de citar:}

Guerra, Rodrigo Andrés. "Tolerancia de la imprecisión en el estado de necesidad." Revista CES Derecho. Vol. 11, No. 1, enero a junio de 2020, 3-27.

\section{Open access}

Términos de uso

Licencia creative commons Etica de publicaciones

Revisión por pares

Gestión por Open Journal System DOI: http://dx.doi.org/10.21615/

cesder.11.1.1

ISSN: 2145-7719

\section{Sobre el artículo:}

* Esta investigación ha sido desarrollada a partir de ideas propuestas en la tesis doctoral titulada "Estado de necesidad como conflicto de intereses: Una propuesta de interpretación desde la inevitabilidad", publicada en Ediciones Olejnik, Santiago de Chile, 2017. Este artículo monográfico es resultado de un trabajo redactado en el marco del proyecto de investigación Fondecyt NN 11190024 "Delimitación del miedo insuperable ante el estado de necesidad".

\section{Resumen}

En atención a la dogmática comparada, especialmente presente en Alemania, y con ocasión del estado de necesidad previsto en el artículo $10 N^{\circ} 11$ del Código Penal chileno, la investigación se hace cargo de la problemática del efecto justificante o exculpante de la eximente y propone una tolerancia de la imprecisión en torno a los efectos del estado de necesidad el modelo jurídico penal chileno. En lo fundamental se considera admisible un grado de indeterminación en torno a estos, aun en un campo de divergencia dogmática, en la medida en que se adopte una interpretación que explique las razones filosóficas y jurídicas de esta imprecisión.

Palabras claves: Intolerancia de la imprecisión, estado de necesidad, interpretación teleológica.

\section{Abstract}

In view of the comparative dogmatism, especially present in Germany, and on the occasion of the state of necessity foreseen in Article 10 No. 11 of the Chilean Criminal Code, the investigation takes into account the problem of the justifying or exculpatory effect of the defense and proposes a tolerance of the imprecision around the effects of the state of necessity the Chilean criminal legal model. In the main, a degree of indetermination around these is considered admissible, even in a field of dogmatic divergence.

Keywords: Intolerance of imprecision, state of necessity, teleological interpretation.

\section{Introducción}

\section{Problema y propósitos}

El Código Penal chileno contiene, en su título relativo a las eximentes de responsabilidad, una disposición de aplicación general que regula el estado de necesidad. Esta indica en su encabezado, en la regulación del art. $10 \mathrm{~N}^{\circ} 11$, que "el que obra para evitar un mal grave para su persona o derecho o los de un tercero", lo que permite la lesión de todo derecho'. El obrar en estado de necesidad puede traer aparejado una multiplicidad de resultados, sea por la vía de afectación de la propiedad, el honor e incluso la integridad corporal, sea en virtud de situación de peligro actual o inminente, como ocurre en situaciones de violencia intrafamiliar, casos de antropofagia, etc.

1. En este contexto, Vargas indica que el art. $10 \mathrm{~N}^{\circ} 11$ dejaría fuera bienes jurídicos como la seguridad colectiva o pública en la línea de la legítima defensa y otros modelos legislativos que tratan el estado de necesidad (Vargas, 2013a, p. 751). Sin embargo, esto no es razón suficiente para establecer que el art. $10 \mathrm{~N}^{\circ} 7$ acepta expresamente a una mirada colectiva o institucionalizada en el estado de necesidad. Lo último. porque el art. 145 del Código Penal chileno lo hace al señalar que en razón de la justicia y la humanidad es posible la violación de morada. 


\section{Sobre los autores:}

1. Doctor en Derecho, Catedrático de Derecho Penal, Universidad de los Andes, Santiago, Chile.
Por tanto, en vez de dejar la aplicación de la eximente al juego utilitarista de la ponderación de intereses, la dogmática decide orientar su interpretación mediante el análisis del contenido de un concepto jurídico indeterminado que, específicamente, contempla la disposición: la palabra mal². La norma en cuestión alude al estado de necesidad de la siguiente manera:

“Art. 10. Están exentos de responsabilidad criminal: 11. ${ }^{\circ}$ El que obra para evitar un mal grave para su persona o derecho o los de un tercero, siempre que concurran las circunstancias siguientes: $1^{\text {a }}$. Actualidad o inminencia del mal que se trata de evitar._2 $2^{\text {a }}$ Que no exista otro medio practicable y menos perjudicial para evitarlo._3 ${ }^{a}$. Que el mal causado no sea sustancialmente superior al que se evita._ $4^{a}$. Que el sacrificio del bien amenazado por el mal no pueda ser razonablemente exigido al que lo aparta de sí o, en su caso, a aquel de quien se lo aparta siempre que ello estuviese o pudiese estar en conocimiento del que actúa".

Con esta norma, que reproduce en lo esencial la propuesta del modelo suizo de Carl Stooss, el legislador pretendió anticipar y resolver una cuestión que ha sido objeto de intenso debate en la dogmática chilena, especialmente en el ámbito de la teoría del derecho, que se manifiesta en lo siguiente: ¿cuáles son los requisitos que han de verificarse para que se pueda dar por acreditada la presencia del estado de necesidad en situaciones extraordinarias de peligro actual o inminente - generalmente trágicas y filosóficamente sofisticadas - y la asignación de un efecto particular, sea justificante o exculpante, en su operación, sobretodo en el caso de la muerte de personas que reciban el impacto de tales acciones o cursos de salvación?

En este contexto, las posiciones dogmáticas en Chile se han enfrentado a dificultades al determinar la presencia de uno u otro efecto en el estado de necesidad. Sin embargo, existen indicios en el pensamiento filosófico de Greenawalt de que la complejidad de estas situaciones no puede ser tratada desde la regulación del Código Penal alemán, en los cuales se identifican requerimientos explícitos de justificación y exculpación, al mismo tiempo que su impacto, en situaciones de violencia contra la mujer, y la consiguiente relevancia social de la problemática, favorecen abstenerse de observar, previamente, un efecto justificante o exculpante en la regulación del art. $10 \mathrm{~N}^{\circ} 11^{3}$. A consecuencia de ello, debemos reconocer la necesidad de revisión de esta discusión, aún en curso, en torno a los efectos del estado de necesidad del art. $10 \mathrm{~N}^{\circ} 11$.

El aspecto más característico del problema, desde un punto de vista teórico-filosófico es que las dificultades no se refieren solo a identificar un efecto justificante o exculpante, entendiendo por tal el cumplimiento de los requisitos de una norma permisiva o la decisión de no sancionar ante la inexigibilidad de una conducta. Por el contrario, la problemática se caracteriza, en atención al estado actual de la disciplina, en el presupuesto conceptual sobre el que se asienta la disposición del artículo $10 \mathrm{~N}^{\circ} 11$, cual es la existencia de una sola regulación del estado de necesidad que, a casos en los cuales se sacrifique la propiedad u otros bien jurídicos, sea capaz de entregar, de forma previa a la resolución del caso, parámetros de justificación o exculpación. Por la relevancia asignada a esta cuestión, es que la problemática hemos decidido tratarla a través del concepto de Greenawalt denominado tolerancia de la imprecisión, denominación que, si bien no es global, nos ha parecido adecuado reconocerla en este artículo ${ }^{4}$. 2. Respecto de las dos vías filosóficas de interpretación que existen en torno al principio del interés preponderante en el estado de necesidad, vease (Guerra, 2017 passim).

3. Respecto de esta problemática en el caso de Karina Sepúlveda, véase (Guerra, 2014, passim). En este caso Sepúlveda decidió matar a su pareja producto del reiterado maltrato que infligió en esta por más de 20 años.

4. La categoría que ha sido enunciada en la doctrina chilena en (Guerra, 2017, p. 386). Sin embargo, en este trabajo entregamos una reflexión orgánica que supera con creces lo expuesto en la última obra recientemente enunciada. 
Debe indicarse que la justificación o exculpación no puede reconducirse a un monopolio dogmático, el cual se traduce, exclusivamente, en utilizar - a modo de anteojeras - el modelo jurídico alemán, esto es, los parágrafos $\S \S 34$ y 35 del StGB para comprender el estado de necesidad chileno del artículo 10 N 11. Así las cosas, si bien se pretende, en un sector de la doctrina, extrapolar la configuración del modelo alemán a la regulación que presenta el art. $10 \mathrm{~N}^{\circ} 7$ y $\mathrm{N}^{\circ} 11$, respectivamente, de modo que se dificulta encontrar otra solución que la del sistema enunciado, nos parece una perspectiva que elude las dificultades de esta posición.

En consecuencia, siendo consustancial a una noción de justificación y exculpación, propia de la tolerancia de la imprecisión, buscamos desmostar que no es posible calificar el efecto del estado de necesidad a través de un ejercicio intelectual que, forzadamente, pretenda utilizar los presupuestos del modelo alemán, sin reflexionar acerca de su conveniencia.

El fenómeno de la doctrina de la dualidad, que empieza a apreciarse en el siglo XX, se ha concentrado, especialmente, en la discusión teórico-filosófica del estado de necesidad alemán, así como en los cambios experimentados en su regulación, si bien se extiende también, aunque con menor fuerza, a la regulación de otros ordenamientos jurídicos. En todo caso, la fuerte incidencia de casos de laboratorio de estados de necesidad en que se tratan - teóricamente - los efectos atribuidos al mismo, ha llevado a que se suela asociar la problemática de su efecto justificante con la primacía del principio del interés preponderante. Se trata, como se puede observar, de un principio que requiere nuevas propuestas interpretativas.

De ahí que no llame la atención que la cuestión constituya una arista importante en la discusión contemporánea que, en torno a los parámetros filosófico-conceptuales del estado de necesidad, incide en el tratamiento del principio de solidaridad y responsabilidad ${ }^{5}$. Por su carácter explicativo para el sistema jurídico chileno, conviene tener presente algunos de los casos más emblemáticos que dan cuenta de esta problemática en el derecho comparado. Debe destacarse que en estos casos la discusión, no se limitó a una cuestión meramente fáctica, extendiéndose a una serie de problemáticas conceptuales en torno al estado de necesidad, de los que, empero, se tendrá que prescindir en este trabajo, porque se enfocará solo en el análisis conceptual de los efectos que contempla el art. $10 \mathrm{~N}^{\circ} 11^{6}$.

Ahora bien, en la jurisprudencia chilena y comparada han existido casos que recaen sobre el estado de necesidad, en los cuales se han producido de modo ostensible efectos significativos para la vida o la salud de las personas, si bien no porque ellos existan (considérese en el efecto exculpante atribuido al uso del estado de necesidad en casos en los cuales se termina con la vida del maltratador y especialmente en los que las mujeres no pueden enfrentar el peligro a través de otros medios menos lesivos, etc.) sino por la tendencia existente entre nosotros a ver en estos, caracterizados por la dificultad de determinar su efecto justificante o exculpante, un espacio de indeterminación entre la ejecución de la conducta y el daño producido.

Es posible sospechar, que con la superación de esta cuestión se planteen también, junto con la cuestión de la eventual responsabilidad penal del agente necesitado, interrogantes sobre la existencia de un nexo causal entre la creación la situación de peligro y dónde recae el resultado lesivo en situaciones de estado de necesidad. Sin 
embargo, este trabajo tiene por finalidad el debate en torno a los efectos del estado de necesidad en el ordenamiento jurídico-positivo. Problemática que se desarrollará en los siguientes apartados, en los cuales se expondrá el estado de la cuestión en la doctrina nacional y se tomará posición al respecto.

Sobre la base de lo anterior se emprenderá, al final de la investigación, una valoración crítica del art. $10 N^{\circ} 11$, entendiendo, que éste no representa más que un terreno fértil para una discusión que resulta obligatoria en la dogmática actual, con independencia de la regulación existente en el sistema jurídico chileno, como por lo demás lo demuestra la discusión de la doctrina chilena, que se caracteriza, ciertamente, como se ha observado, por responder a los parámetros de la regulación del modelo jurídico alemán 7 . Con todo, antes de abordar esta materia resulta necesario una reflexión sobre el sentido y el alcance de la materia en la dogmática chilena ${ }^{8}$.

\section{Posiciones interpretativas antes del art. $10 \mathrm{~N}^{\circ} 11$}

Podría provocar curiosidad el interés manifestado en torno a los efectos del estado de necesidad. Superadas las tesis de un posible dualismo en el modelo alemán, apenas se discute si el estado de necesidad ha de contemplar un efecto justificante y exculpante en su regulación positiva, como se observa en el artículo $10 \mathrm{~N}^{\circ} 11$ del Código penal chileno. En este contexto, se presentan posiciones en la doctrina chilena a favor de regular dichos efectos en el sistema jurídico positivo, posición que aquí, no obstante, no podemos compartir con importantes matices.

En sus inicios, antes de la existencia del estado de necesidad del art. $10 \mathrm{~N}^{\circ} 11$, la dogmática chilena reconoce en el artículo $10 N^{\circ} 7$ del Código penal solo un efecto justificante en el estado de necesidad, porque observar en la segunda circunstancia de la disposición la exigencia de provocar un mal inferior al que se pretende evitar. Ciertamente, esta idea surge de la dogmática alemana a través del principio del interés preponderante y se inspira en la teoría de la diferenciación entre un efecto justificante y exculpante (Etcheberry, 1998ª p. 263; Cury, 2005, p. 362; Novoa, 2005a p. 363; Ortiz, 1933, p. 46; Fontecilla, 1964, pp. 690 y 702; Vial del Río, 1969, p. 38; Cousiño, 1979b, pp. 362 y ss.; Hernández, 2011b, p. 271). Así, la dogmática chilena se ocupaba del efecto exculpante del estado de necesidad cuando se trata de un mal equivalente o superior al que se pretende evitar a través del miedo insuperable, la fuerza irresistible o el ejercicio legítimo de un derecho ${ }^{9}$, considerando la regulación que presentaba el art. $10 N^{\circ}$ 7. Sin embargo, algunos se oponen a esta solución y reclaman la necesidad de regular un estado de necesidad exculpante.

Descontado que el estado de necesidad puede presentar un efecto justificante y exculpante en la exención de responsabilidad penal, no parece admisible desconocer la relevancia de esta dualidad, al menos en acciones cuya realización exige la afectación de algún interés jurídico. Ciertamente, es frecuente que el punto de partida del estado de necesidad es la constatación de una situación de peligro. Cuando este elemento está presente, la esencia de la eximente se acepta sin más en la doctrina actual.

Por ello, nos parece que este requisito cumple una función primordial. Es decir, un filtro en la selección de los casos que posteriormente requieren cumplir con el resto de los requisitos del artículo $10 N^{\circ} 11$. De ahí que antes de la formulación del art. 10

7. Problemática que hemos tratado en profundidad en (Guerra 2017, passim).

8. Tendencias en tornos a los efectos del estado de necesidad que se observan detalladamente en (Guerra, 2017, passim)

9. Sin embargo, este criterio de diferenciación entre males, según Wilenmann:

"extendido en el mundo hispanoparlante de diferenciación [...] que es completamente errado, a saber, si hay preponderancia del mal a evitar frente al mal causado, hay justificación (y limitación a la propiedad ajena en el caso chileno); si hay equivalencia o preponderancia del mal causado en caso de conflicto de intereses, hay exculpación", (Wilenmann, 2014ª p. 219, nota. 12). 
№ 11 la doctrina chilena, en atención a la reforma legal que permitió la incorporación del estado de necesidad justificante del $\S 34$ y exculpante del $\S 35$ en el Código penal alemán, acepta la posibilidad de contemplar la existencia de una sola regulación que contemple ambos efectos.

En esta línea, un sector de la doctrina sostuvo que las vacilaciones interpretativas en torno a los efectos se generan por la diversidad de casos que puede comprender el estado de necesidad. Así, el problema continúa en establecer si el estado de necesidad responde a una causal de justificación o exculpación y si se requiere de una regulación que represente la dualidad. Explicación que se manifiesta en la doctrina chilena -en el caso de Cousiño- a partir del caso del caminante, que afectado por el hambre mata a una oveja para comer su carne, con la obligación de dejar el cuero y su lana en la cerca para demostrar su falta de ánimo de apropiación ${ }^{10}$.

Pero la coherencia con incorporar una sola disposición que contemple ambos efectos es, desde la perspectiva de Cousiño, deseable en el ordenamiento chileno. Así pues, este consideró que adoptar una disposición como la del § 54 del antiguo Código penal alemán no hubiera generado una discusión entre tesis unificadoras o diferenciadoras, respecto de los efectos del estado de necesidad. Precisamente, el encabezado de la disposición § 54 indicaba que "no existen acciones punibles cuando.... La disposición con este encabezado denota la imprecisión en la demarcación de los efectos de la eximente. Es decir, ante la ausencia de antijuridicidad o culpabilidad en la acción del agente necesitado. De este modo, todo estado de necesidad requiere que se confirme una situación de peligro actual o inminente-aun cuando exista incertidumbre en torno al efecto justificante o exculpante de la acción-, porque será necesario que en dicha acción se constate la presencia de los requisitos de subsidiariedad, proporcionalidad y ausencia de provocación o tolerancia de la situación. Sin embargo, las discusiones que se generaron a partir del $\S 54$ dieron origen a una reforma del CP en Alemania. Esta reforma introduce las actuales disposiciones: el $\S 34$ (estado de necesidad justificante) y § 35 (estado de necesidad exculpante). Modificación que colocó a la teoría de la diferenciación en una posición dominante en el modelo alemán ${ }^{11}$. Sin embargo, Cousiño no es partidario de esta última regulación, porque es posible desprender del $\S 54$, a través de la ponderación de intereses, tanto un efecto justificante como exculpante. Así, indicó que "el problema del § 54 del Código Penal alemán, si existiese en Chile un precepto semejante, no habría sido objeto de posiciones tan absolutas" (Cousiño, 1979b, p. 369).

Ahora bien, un sector de la dogmática chilena reconoce, antes de la existencia del art. $10 N^{\circ} 11$, en una regulación unitaria del estado de necesidad. Así, los beneficios de este modelo resultan evidentes en torno a las variantes que presentan las situaciones de peligro, y que requieren diferenciar, conforme a la valoración del hecho conforme a la norma, si la acción en el proceso de subsunción responde a un tipo permisivo o si más bien, en la imputación jurídica, responde a los parámetros de la inexigibilidad. Ello sea que vean en la valoración de la acción la corroboración de los parámetros propios de una norma permisiva, sea que entiendan que se trata de una situación de inexigibilidad atingente a la vis compulsiva. Sin embargo, esta propuesta de considerar en una sola regulación dos efectos del estado de necesidad no ha estado exenta de discusión en la doctrina. Así, Politoff, Matus y Ramírez observan que en otros modelos comparados, como en el Código penal español en el art. $20 \mathrm{~N}^{\circ} 5$ e italiano en el art. 54, se contempla una sola causal de estado de necesidad. Estas causales contendrían tanto el efecto de justificación como de exculpación. Modelos, 
como podremos darnos cuenta, que inciden en la formulación del art. $10 N^{\circ} 11$. Sin embargo, estos autores sostienen que, en los modelos enunciados, la "doctrina de dichos países ha debido lidiar con el pie forzado de esas regulaciones especiales, más o menos afortunadas, pero que no es del caso analizar a la luz de nuestro derecho, y mucho menos pretender trasplantar esas regulaciones especiales" (Politoff, 2013, pp. 345-346). Según Politoff, Matus y Ramírez, la solución a la falta de un estado de necesidad exculpante no se encuentra en crear una disposición jurídica que contemple ambos efectos.

En relación con lo anterior, Couso reconoció que la disposición del art. 20 N 5 del modelo español dio lugar a diversas interpretaciones en la doctrina española, entre ellas, la teoría de la diferenciación y de la unidad. La primera considera que, si estamos ante males iguales, la disposición del art. 20.5 contempla un estado de necesidad exculpante, pero si el mal causado es inferior al evitado, tiene un efecto justificante. En cambio, la teoría de la unidad contempla la justificación cuando el mal causado sea inferior o igual al evitado (Couso, 2006, p. 523). El fundamento de lo expuesto radica, según la palabras de Couso, en

"que la causación de un mal jurídico se ve compensada por el hecho de que con esa acción se evita otro mal equivalente o mayor, con lo cual el legislador ya no quiere dirigir una prohibición penal, pues ésta tiene precisamente una finalidad preventiva, para la protección de bienes, y, en este caso, no tiene sentido que proteja un bien jurídico de un mal, a costa de impedir la evitación de otro mal equivalente o superior" (Couso, 2006, p. 524).

También Couso estimó que, en la línea de Mir y en cierta medida Gimbernat, es posible interpretar esta norma del modelo español como una disposición unitaria del estado de necesidad justificante. Sin embargo, el autor no niega la alternativa de construir analógicamente un estado de necesidad excluyente de la culpabilidad. Necesidad analógica que reserva para aquellos casos en que el agente actúa frente a una situación de necesidad, disminuyendo significativamente en su motivabilidad. Situación en la que no se produce la adecuación y proporcionalidad del mal provocado en referencia al que se pretende evitar.

Tampoco se opone a lo dicho la formulación que actualmente presenta el artículo 10 $N^{\circ} 11$, que, sin perjuicio de castigar la regulación del Código penal alemán, no deja de construir tácitamente sobre ella, en especial a la hora de aceptar la subsistencia dogmática del estado de necesidad defensivo y agresivo en la justificación, porque menos diferencias exhibe respecto de la formulación en un sector amplio de la doctrina chilena.

Última relación que pareciera ser ineludible en casos de estado de necesidad justificante. Pero más allá de eso, Couso sería partidario de la teoría de la unidad al interpretar el art. 20.5 del CP español. No obstante, defiende la teoría de la diferenciación, porque acepta la posibilidad de la construcción de un estado de necesidad excluyente de la culpabilidad por analógica (Couso, 2006, pp. 523- 524). Esta declaración interpretativa se sostiene en Gimbernat que, ante la equivalencia del mal causado y evitado, defiende el estado de necesidad justificante.

Así las cosas, Couso sustenta que la argumentación de Gimbernat lo conduciría a justificar la conducta realizada por un agente "menos motivable, pero aún motivable," (Couso, 2006, p. 525) en situaciones de inexigibilidad. Esto, inclusive si el mal causado 
fuese superior al que se pretende evitar. Pero en situaciones de estado de necesidad exculpante o miedo insuperable, el legislador renuncia a sancionar el hecho, porque lo considera un límite a las pretensiones preventivo-punitivas del Estado, conforme al principio de que no hay pena sin culpabilidad.

Ahora bien, lo anterior no implica desconocer que la determinación del efecto le corresponde al intérprete porque la regulación responde a una norma con un significado contingente. Lejos de ser un despropósito, como afirman los partidarios de una regulación unitaria de estado de necesidad, la idea de una regulación que sea tolerante con la imprecisión se sustenta sobre la base de un valor jurídico esencial, sucintamente en la seguridad jurídica. Esta nos lleva "a la formación de un sistema... a través de un derecho consecuentemente ordenado, dominado por pocos principios abarcables... que por una inabarcable pluralidad de normas particulares inconexas y, con ello, fácilmente susceptibles de contradecirse" (Canaris, 1998, p. 26).

En este orden de ideas, sucede simplemente que, con independencia del actual modelo alemán de estado de necesidad, el derecho chileno puede decidir adoptar una regulación que solo reconozca los requerimientos básicos de todo estado de necesidad, en atención a los objetivos de la eximente. En esta línea, se puede indicar que para el derecho penal el estado de necesidad es una eximente y, en cuanto tal, no es necesario que responda a un criterio de causalidad que incorpore las estructuras de la imputación jurídico-penal.

Última posición que, siguiendo la posición de Couso, actualmente se relaciona con la idea de que con la incorporación en el numeral 11 del Art. 10, de una eximente estado de necesidad mucho más extensa que la del numeral $7^{\circ}$ y en la que "el tratamiento de los contornos del estado de necesidad del numeral $7^{\circ}$ en buena medida pierde importancia práctica y exige un tratamiento unitario con los del numeral $11^{\circ}$ (Couso, 2011b, p. 234-235).

Con todo, estos razonamientos en la dogmática chilena nos muestran que, antes de la existencia del art. $10 \mathrm{~N}^{\circ} 11$, se acepta e incluso reconoce la posibilidad de contemplar en una disposición de estado de necesidad tanto un efecto justificante como exculpante. Ello, según el caso de Cousiño, respecto del modelo chileno, y de Couso, en atención al modelo español, desde una posición, ciertamente, favorable a contemplar ambos efectos en una disposición; postura, esta última, que diferiría de lo expresado por Politoff, Matus y Ramírez. En este orden de ideas, podemos observar en la doctrina que no existen inconvenientes para admitir la existencia de una regulación del estado de necesidad que contemple ambos efectos. Así, en el estado de necesidad se reconoce el tratamiento dogmático del mal desde tres variantes: un mal inferior, equivalente o superior al que se pretende evitar.

Dentro de estas variantes que considera la dogmática, las dos últimas son reconducidas al estado de necesidad exculpante. Sin embargo, con la consideración de la categoría del estado de necesidad defensivo y agresivo, propia del modelo alemán, sería posible justificar, en el primer caso, la ejecución de un mal equivalente al que se pretende evitar en materia penal por existir un peligro que proviene de una fuente sobre la cual recae la acción del agente. Observación que no sería admisible en el estado de necesidad agresivo que, debido a la existencia de un deber mínimo de solidaridad, solo permite causar un mal inferior al que se pretende evitar. 
Precisamente, conforme con lo expuesto en esta sección, la cuestión ha motivado una reflexión jurídica en torno al estado de necesidad-no sólo en el ámbito penal, sino que también en el derecho civil-, lo que dista de ser un culto por la erudición del pasado. La problemática revela que si la discusión de los efectos del estado de necesidad pudo llegar a prescindible, solo lo fue a la luz de la relativa trivialidad de la regulación alemana, contexto en el cual la explicación de la eximente -aparentemente- no genera mayores dificultades, de modo que directamente tiende a coincidir con la experiencia comparada y, de ese modo, con el sentido común, con lo cual explicaciones de lege lata y lege ferenda tiende a confundirse en la literatura nacional.

A continuación, entregaremos un breve panorama en torno a las tendencias interpretativas que se presentan dogmáticamente en torno a los efectos del art. $10 \mathrm{~N}^{\circ} 11$. Estas solo son algunas consideraciones conceptuales en relación a las particularidades y dificultades que presenta dicha disposición y la plataforma conceptual sobre la cual se asienta la creación del artículo $10 \mathrm{~N}^{\circ} 11$.

\section{Líneas interpretativas con posterioridad a la creación del art. $10 \mathrm{~N}^{\circ} 11$}

\section{Posiciones dualistas o mixtas en la doctrina chilena}

En la doctrina chilena, como observamos en la sección anterior de este artículo, existen diferentes posiciones en torno a los efectos del estado de necesidad antes de la creación del art. $10 \mathrm{~N}^{\circ} 11$. Si bien hay consenso en el reconocimiento del efecto exculpante, ello no erradica la problemática de aceptar en una sola regulación también un efecto justificante. Con la incorporación del art. $10 N^{\circ} 11$, a propósito de la violencia que se ejerce contra la mujer (Santibáñez y Vargas, 2011, pp. 193-199), se comienza a gestar un modelo de interpretación que admite dos efectos en la regulación. Es importante indicar que la selección del modelo suizo no fue aleatoria para el creador de la norma, porque fue resultado de un análisis detallado del art. 20.5 del modelo español, que trata conjuntamente el estado de necesidad justificante y exculpante; del art. 54 del CP italiano, que contempla solo aparentemente el exculpante, y finalmente, la fórmula del CP alemán, que contiene el § 34 y el § 35, última regulación que se comporta para Cury más como si fuera un tratado que un CP (Cury, 2013, pp. 251-252 y 257-258). Esta concepción permite formular la regulación del art. $10 \mathrm{~N}^{\circ}$ 11. Así, un sector dominante en la doctrina sustentará que el art. $10 \mathrm{~N}^{\circ} 11$ tiene dos efectos, fundado en que el creador de la norma tomó de referencia el modelo suizo y por la redacción de las exigencias de la disposición (Couso, 2011b, p. 235; Santibáñez y Vargas, 2011, p. 198; Vargas, 2013a, p. 761; Acosta, 2013, p. 702; Sepúlveda, 2012, p. 181; Ossandón, 2012, p. 339). Postura que se contrapone con un sector minoritario, que solo le atribuye un efecto exculpante a la disposición (Hernández, 2011 b, pp. 270 271; Mañalich, 2013b, pp. 720-721; Náquira, 2015, pp. 387 y 614-630)12. Efectivamente, Cury pretendió concentrar el modelo suizo en una norma que tuviera una terminología semejante a las eximentes del art. 10. De esta forma, determinó que resultaría más familiar la disposición a los jueces, siguiendo el estilo del CP. Si bien esta posición es relevante desde una perspectiva teológica subjetiva, es necesario indagar en los orígenes y la plataforma conceptual sobre la cual se asienta la norma. Ello, para

12. Por otra parte, debemos indicar que existe un autor que recientemente comprende solo un efecto justificante en la disposición, desplazando el exculpante al miedo insuperable del art. $10 \mathrm{~N}^{\circ} 9$. En este sentido, van Weezel sostiene que el art. $10 \mathrm{~N}^{\circ} 11$ comprende dos formas de estado de necesidad justificante: el estado de necesidad defensivo y agresivo. Funda el autor sus argumentos en que la cuarta circunstancia del art. $10 \mathrm{~N}^{\circ} 11$ solo apunta a indicar que no se admite a la inexigibilidad cuando sea posible exigir otra conducta al agente, en que la inexigibilidad es predominantemente personal sin poder aludir a terceros y en que ni tanto la subsidiariedad como la proporcionalidad encuentran espacio adecuado en la inexigibilidad, véase (van Weezel, 2015, p. 352) Así. la circunstancia tercera de la disposición en comento "funciona como reguladora entre los dos estados de necesidad justificantes: en su límite opera solo en caso de estado denecesidad defensivo; para que justifique en los casos de estado de necesidad agresivo, en cambio, se requie aue el balance esté muy por sobre ese límite mínimo", (van Weezel, 2015, p. 354). 
responder qué efectos contempla el art. $10 N^{\circ} 11$. Nadie que sustente una posición mixta ha realizado un análisis de estas características. En otras palabras, no se ha investigado sobre cuáles serían las razones jurídicas y dogmáticas que permiten sostener la posibilidad de contemplar en una regulación dos efectos e identificar por qué es una alternativa adecuada en nuestro ordenamiento.

A continuación, debemos indicar cuáles son los argumentos que sustenta la posición minoritaria que hemos denominado unitaria, para considerar que el art. $10 \mathrm{~N}^{\circ} 11$ solo contemplaría aparentemente un efecto exculpante.

\section{Posiciones unitarias en torno a los efectos del estado de necesidad}

Dentro del grupo de autores que consideran que la disposición del art. $10 \mathrm{~N}^{\circ} 11$ tendría solo un efecto exculpante, posición que hemos denominado unitaria, podemos mencionar a Hernández, Mañalich y Wilenmann. Hernández señala que no se trata de una causal de justificación, debido a las aseveraciones realizadas durante la tramitación de la disposición y la subsistencia del estado de necesidad del art. $10 \mathrm{~N}^{\circ}$ 7. Además, la disposición del art. $10 N^{\circ} 11$ muestra una naturaleza que difiere de un modelo justificante con las exigencias de la tercera y cuarta circunstancia de la norma. Así, la primera establece que el mal causado no sea sustancialmente superior al que se evita y la segunda apunta a que el sacrificio del bien amenazado no sea exigible al agente (Hernández, 2011b, p. 270).

Hernández enuncia esta interpretación considerando tanto la historia de la ley como el valor objetivo de la norma. Sin embargo, deja fuera la finalidad del creador de la disposición. En este contexto, Hernández no considera en su análisis que la disposición siga el modelo del Código penal suizo. Este declara que la circunstancia $4^{a}$ del art. $10 N^{\circ} 11$, que alude "a que el sacrificio del bien amenazado no sea exigible" (Hernández, 2011b, p. 270; Maurach, 1994, p. 568) remitiría expresamente "a la idea de inexigibilidad, que, cumplida la exigencia de subsidiariedad de la circunstancia $2^{a}$, estaría fuera de lugar si se trata de una genuina causa justificante; lo primero, porque al menos desde el punto de vista de la „teoría de la diferenciación”, ampliamente dominante en el debate comparado [...], sólo puede estar justificada la irrogación de un mal menor al que se evita [...], a lo que en el caso chileno se suma que la eximente no sólo procede ante igualdad de males, sino incluso cuando se ocasiona un mal mayor, aunque no "sustancialmente superior", que el que se evita" (Hernández, 2011b, p. 271; Maurach, 1994, p. 568). Lo que manifiesta Hernández implica rechazar tajantemente la posibilidad de comprender en el estado de necesidad del art. $10 \mathrm{~N}^{\circ} 11$ efectos tanto justificantes como exculpantes. Si bien al dirigirnos a la cuarta circunstancia del art. $10 \mathrm{~N}^{\circ} 11$ se observa la idea de inexigibilidad, esto no desarticularía, necesariamente, el efecto justificante de la disposición del art. $10 \mathrm{~N}^{0} 11$, porque la ponderación, con importantes limitaciones, podría entregar aquellos criterios necesarios para distinguir entre las acciones que podrían ser comprendidas en el marco de la inexigibilidad de otra conducta o aquellas que solo harían referencia a una causal de justificación ${ }^{13}$.

13. En este sentido, se reconoce la posibilidad de considerar la ponderación como un criterio diferenciador en (Cousiño, 1979b, p. 369; Jiménez de Asúa,1961, p. 360). Por otra parte, se ha señalado que el principio de proporcionalidad no sería incompatible con el de interés preponderante, porque la proporcionalidad constituiría el presupuesto para poder realizar una comparación entre males, reconociendo el restrictivo campo de aplicación del art. 10 $N^{\circ}$ 7, en (Fuentes, 2009, pp. 76-77; Politoff, 2000, p. 299). 
En este orden de ideas, la doctrina mayoritaria en Chile ya entendía que la cuarta circunstancia del actual art. $10 \mathrm{~N}^{\circ} 11$ se encontraba presente de manera “implícita en el art. 10 N 7 [...]"(Cury, 2013, p. 255)². También la sentencia del Juzgado de Arauco de 16 de diciembre de 1937, al fundamentar la causal de justificación del art. 10 N 7 del CP habla de una cierta "inexigibilidad" (García, 1999, p, 384), con anterioridad al actual art. $10 N^{\circ} 11$. Por ende, comprender el deber de soportar o no el peligro inminente, como parte de la naturaleza del estado de necesidad, reafirma aparentemente su carácter subsidiario; esto es, la selección del medio menos lesivo para enfrentar el peligro. En este sentido, el propósito del creador del artículo $10 \mathrm{~N}^{\circ} 11$ fue una disposición amplia, como la del art. 34 del CP suizo o del art. 54 del CP italiano, y de evitar incorporar una lista de casos, como lo hace el §35 del CP alemán (Cury, 2013, p. 261). Si bien la idea de considerar la ponderación, para distinguir entre los efectos justificantes y exculpantes de la disposición del art. $10 \mathrm{~N}^{\circ}$ 11, puede parecer desconcertante o perturbadora, cabe recordar que antes de la incorporación del $\S 34$ (estado de necesidad justificante) y $\S 35$ (estado de necesidad exculpante) en el CP alemán existía solo una disposición referente al estado de necesidad: el § 54, que dio lugar a la contraposición entre la teoría de la unidad "Einheitstheorie" y la teoría de la diferenciación "Differenzierungstheorie". Panorama en Alemania, respecto de la interpretación del $\S 54$, se podría haber resuelto -según Jiménez de Asúa- al "interpretar ese $\S 54$ en el sentido de que, por no referirse a exigencia alguna sobre el valor proporcional del bien salvaguardado, lo mismo comprendía casos justificados como inculpables" (Jiménez de Asúa, 1961, p. 360).

En la misma línea, Cousiño en la doctrina chilena indicó que de haberse incorporado una disposición como la del § 54 en Chile, se podría haber resuelto el problema de los efectos de la resolución desde la ponderación (Cousiño, 1979b, p. 369). Por ello, una disposición como la del $\S 54$ "no habría sido objeto de posiciones tan absolutas [...]" (Cousiño, 1979b, p. 369). Sin embargo, con la introducción de la disposición del art. $10 \mathrm{~N}^{\circ} 11$ se ha dado todo lo contrario, al coexistir una postura unitaria y una mixta respecto de los efectos. Por otra parte, Hernández refuerza el argumento del efecto exculpante del art. $10 \mathrm{~N}^{\circ} 11$ a partir de que el sacrificio del bien amenazado no sea exigible, al remitir la idea de inexigibilidad al cumplimento de "la exigencia de subsidiariedad de la circunstancia $2^{a}$ ", que "estaría fuera de lugar si se trata de una genuina causa justificante" (Hernández, 2011b, p. 271). Sin embargo, debemos recordar que la doctrina siempre vio en el art. $10 \mathrm{~N}^{\circ} 7$ un estado de necesidad justificante, pese a la existencia del requisito de subsidiariedad en la $2^{a}$ circunstancia de la misma disposición. En esta línea, observamos que la subsidiariedad sería un elemento inherente a la naturaleza del estado de necesidad (Cury, 2005, p. 378; Fuentes, 2009, p. 25; Cousiño, 1979b, p. 374; García, 1999, p. 68; Silva Sánchez, 1982, p. 665; von Liszt, 1916, pp. 351-353; Freudenthal, 2006, p. 97) ${ }^{15}$, con independencia de su modalidad justificante o exculpante. Gran parte de la doctrina chilena caracteriza al estado de necesidad desde un conflicto entre dos bienes jurídicos protegidos, intereses o males frente a un peligro inminente (Náquira, 1998, p. 256; Garrido, 2007b, pp. 180, 187 y 189; Politoff y Ortiz, 14. En esta línea, véase (Etcheberry, 1998a , pp. 265 y ss.; Cury, 2005, p. 378; Cousiño, 1979b, pp. 402 y ss.; Politoff, 2000, pp. 298 - 299; Politoff, 1997, p. 388 15. Debemos recordar que la inevitabilidad es parte de la esencia del estado de necesidad, véase (Guerra, 2018, passim). 
2002, p. 140, entre otros). Este peligro inminente solo es evitable a costa de la producción de otro mal para un interés o bien jurídico a través del menos lesivo. En este contexto, la subsidiariedad parecería ser parte fundamental del estado de necesidad (Vargas, 2013a, pp. 749-750).

En contraposición a las posiciones unitarias, Acosta sostiene que el art. $10 \mathrm{~N}^{\circ}$ 11 abarca tanto un estado de necesidad exculpante como justificante, obedeciendo la diferenciación de ellos a la gravedad del mal causado respecto del evitado. Estos estados de necesidad deben cumplir con las mismas exigencias, lo que involucra una objetivación del exculpante (ACOSTA (2013) p. 697). Aunque es correcto afirmar, en la línea de Hernández, que la disposición del art. $10 \mathrm{~N}^{\circ} 11$ "de algún modo "objetiviza" lo que a partir de la valoración de circunstancias se puede considerar una motivación anormal (aunque en el caso en concreto no afecte emocionalmente al sujeto), sea compatible con la idea de inexigibilidad de otra conducta [siendo] evidente para todos aquéllos que ven hipótesis de inexigibilidad en el encubrimiento de parientes (art. 17) o en ciertas hipótesis de obediencia jerárquica [...]" (Hernández, 2011b, p. 271), en realidad la disposición del art. $10 \mathrm{~N}^{\circ} 11$ no busca solo plantear problemas de inexigibilidad, sino más bien un encuentro con la naturaleza justificante del estado de necesidad ${ }^{16}$.

En este contexto, resultaría relevante retomar el estudio dogmático de las posiciones heterodoxas de Mayer y Maurach. Estas posiciones tuvieron un tratamiento exiguo con la reforma al CP alemán que introduce el $\S 34$ y $\S 35$, porque esta acogió expresamente la teoría de la diferenciación en el Código, creando una disposición referente al estado de necesidad justificante ( $\S 34$ ) y exculpante $(\S 35)^{17}$. El estudio de Mayer es interesante, porque reconduce el problema de los efectos del estado de necesidad al concepto que se tenga de antijuricidad ${ }^{18}$. Por otra parte, el estudio de Maurach resulta interesante, porque establece una nueva categoría, denominada responsabilidad por el hecho. Así, este último autor posiciona esta nueva categoría entre la culpabilidad y la antijuridicidad, con el objeto de llevar el problema de la inexigibilidad de otra conducta a la naturaleza misma del estado de necesidad ${ }^{19}$. Sin embargo, esto nos desorientaría en este artículo de nuestro propósito: establecer si el art. $10 \mathrm{~N}^{\circ} 11$ puede contemplar dos efectos.

\section{Advertencia de vicios esencialistas en la posición unitaria}

Mañalich advierte sobre el riesgo de caer en un vicio esencialista a la hora de interpretar el artículo $10 \mathrm{~N}^{\circ} 11$. Este indica que un vicio esencialista

"consistente en asumir que, por su "naturaleza", el estado de necesidad necesariamente tendría que ajustarse a una u otra categoría. Pues esto desconocería que la determinación de si el estado de necesidad es reconocido como causa de justificación, o bien como causa de exclusión de la culpabilidad, es una determinación que depende de una definición legislativa" (Mañalich, 2013b, pp. 717-718).

16. El creador de la disposición del art. $10 \mathrm{~N}^{\circ} 11$ reconoce estos ejemplos como parte del estado de necesidad exculpante, véase (Cury, 2013, p. 262)

17. véase (Cousiño, 1979b, pp. 367-368, notas 877 y 878).

18. Véase (Mayer, 1967, p. 133).

19. Véase (Maurach, 1994, p. 465) 
Conforme con ello, hasta aquí el autor no rechaza la coexistencia de ambos efectos en una disposición de estado de necesidad. Sin embargo, continúa su razonamiento indicando que existirían importantes razones para sustentar que el CP chileno, desde la incorporación del actual art. $10 \mathrm{~N}^{\circ} 11$, seguiría el régimen dualista del CP alemán, pero en los términos de tal regulación: con dos disposiciones aparte. Pareciera que el autor realiza una interpretación que pretende evitar un superposición entre el efecto justificante de la disposición del art. $10 \mathrm{~N}^{\circ} 7$ y el que podría caber en el art. 10 $N^{\circ} 11$ que, por ello, sería solo exculpante.

Ciertamente, determinar el alcance de los efectos del estado de necesidad del art. 10 $N^{\circ} 11$ se desprende de su noción y de la finalidad de la disposición. De esta manera, no basta solo definir desde una interpretación histórica o sistemática, es necesario considerar primero los términos de la ley, pero también la interpretación dogmática del creador de la disposición. En este contexto, Mañalich señala que la circunstancia tercera de la disposición del art. $10 \mathrm{~N}^{\circ} 11$ "tiende a coincidir con el estándar que cabe entender como distintivo del régimen del estado de necesidad defensivo en tanto causa de justificación" (Mañalich, 2013b, p. 719), porque establece que el daño causado no se produzca en desproporción con el peligro que se enfrenta (Mañalich, 2013b, p. 719, nota 11). Sin embargo, desde su perspectiva, el art. $10 \mathrm{~N}^{\circ} 11$ no contendría la exigencia esencial del estado de necesidad defensivo; esto es, que "el peligro para el bien jurídico salvaguardado tenga su origen en la 'esfera de organización' del titular del bien jurídico menoscabado por la respectiva acción de salvaguarda" (Mañalich, 2013b, p. 719).

Ahora bien, debemos preguntarnos si esta última exigencia se encuentra efectivamente en la disposición del § 34 del CP alemán. De la simple lectura de la disposición nos parece que no es posible desprender que el peligro debe provenir de la esfera de organización del titular del bien menoscabado, no obstante admitir que dicho razonamiento pueda verse contenido de forma manifiesta en el $\S 228$ del CC alemán. Mañalich llega a la conclusión de que dada la condición de inexistencia de este último requisito en el art. $10 \mathrm{~N}^{\circ} 11$, "lo prudente es negar la viabilidad de su interpretación como una causa de justificación. Pues sostener lo contrario supondría asumir que el $N^{\circ} 11$ del artículo 10 establecería una causa de justificación consistente en una modalidad de estado de necesidad agresivo de alcance considerablemente más amplio que el del N 7 del artículo 10" (Mañalich, 2013b, p. 720). Mañalich afirma que considerar un efecto justificante en el art. $10 \mathrm{~N}^{\circ} 11$.

"no sólo resultaría asistemático, sino que al mismo tiempo amenazaría con desdibujar los contornos de los deberes de tolerancia correlativos a los derechos de intervención sobre bienes jurídicos ajenos que resultan de la norma permisiva aplicable en situaciones de estado de necesidad agresivo, cuyo fundamento material está constituido por un principio de solidaridad general (mínima)" (Mañalich, 2013b, p. 720).

Así las cosas, nos parece que el hecho de que la disposición del art. $10 \mathrm{~N}^{\circ} 11$ no haga alusión a que "el peligro para el bien jurídico salvaguardado tenga su origen en la "esfera de organización" del titular del bien jurídico menoscabado por la respectiva acción de salvaguarda" no es razón suficiente para excluir de ella un efecto justificativo. Lo anterior, en el entendido de que este requisito también se encontraba ausente en la disposición del $\S 34$ del CP alemán, siendo complementado a través de una interpretación doctrinal analógica del $\S 228$ del CC alemán que dio lugar a una causal de justificación supralegal. 
En cambio, Wilenmann sostiene que el art. $10 \mathrm{~N}^{\circ} 11$ tiene por finalidad incorporar al sistema jurídico una causa de exclusión de culpabilidad para proteger a las mujeres maltratadas de sus maridos abusadores, enfocándose en casos donde la mujer efectivamente lo mata. Así, "se introdujo una disposición en la que la facultad de agresión no se restringiera a la propiedad ajena y cuyas condiciones de procedencia fueran más generosas [...] exigiendo que no exista desproporción grave entre el mal causado por la acción de necesidad y el mal prevenido mediante ella" (Wilenmann, 2014a, p. 218). Pues bien, una regla de estas características -continuando con Wilenmann- nunca puede justificarse por solidaridad "o aquello que se identifique como fundamento del estado de necesidad agresivo" (Wilenmann, 2014a, p. 218). El art. $10 \mathrm{~N}^{\circ} 11$ del $\mathrm{CP}$ en su estructura es incompatible con un estado de necesidad agresivo que autorice lesionar derechos de terceros para salvar bienes del agente de menor entidad. Por ello, estima que la disposición "solo podría ser compatible o bien con el estado de necesidad defensivo o bien con el estado de necesidad exculpante" (Wilenmann, 2014a, p. 218). Este, acertadamente, indica que ni las características fundamentales "del estado de necesidad defensivo (la atribución de competencia respecto al peligro) ni la característica fundamental central del estado de necesidad exculpante (la fijación de criterios absolutos de inexigibilidad de cumplimiento de reglas) pueden encontrarse en el artículo 10 número 11 CP" (Wilenmann, 2014a, p. 218). En efecto, no podemos observar en la disposición un nexo entre la fuente del peligro y la cosa o persona que lo provoca, ni una determinación de efectos.

También Wilenmann indica que la situación de necesidad que regula el art. $10 \mathrm{~N}^{\circ} 11$ del CP sería la del estado de necesidad agresivo e incluso el no haber derogado el art. 10 N$^{\circ} 7$ equivale a mantener "un estrecho estado de necesidad agresivo" (Wilenmann, 2014a, p. 219). Regulación del estado de necesidad que, en consideración de ambas disposiciones, le parece "sistemáticamente injustificable" (Wilenmann, 2014a, p. 218). Sin embargo, no seguimos aquí este razonamiento, porque el estado de necesidad del art. $10 \mathrm{~N}^{\circ} 11$ en el hecho no plasma estas categorías en el ordenamiento jurídico-penal. La norma no alude al nexo de la cosa o persona con la fuente de peligro (estado de necesidad defensivo) o a su ausencia, exigiendo que el que se pretende evitar sea desproporcionadamente grave al causado (estado de necesidad agresivo). Nos parece que la palabra sustancialmente busca contemplar todas estas variantes restringiéndolas al campo dogmático. La regulación del art. 10 № 11 no se restringe a una u otra categoría; esto es, al estado de necesidad defensivo o agresivo. Así, incorporarlas impone un criterio moral unitario que el legislador buscó evitar. Lo expuesto, sobre todo considerando la diversidad de interpretaciones que existen a la construcción del nexo del peligro con la persona o cosa sobre la cual recae la acción en el estado defensivo.

Si bien el art. $10 N^{\circ} 11$ genera diversos problemas interpretativos, entrega la oportunidad de plantear una solución que sea coherente con la incorporación de esta disposición; esto es, comenzar con una reflexión del estado de necesidad, de sus fundamentos, sin desconocer los modelos que reconocen nuestra literatura y jurisprudencia. Como se observa, en la dogmática nacional, tanto la posición unitaria como mixta han dejado en el olvido la discusión sobre cuáles son los fundamentos que llevan a la incorporación en el ordenamiento jurídico penal del art. $10 N^{\circ} 11$, en circunstancias de que su plataforma conceptual se convierte en el punto decisivo para interpretar la disposición. En lo que sigue, pretendemos dar cuenta de una solución a este problema ignorado en la literatura nacional. De conformidad con ello, constatamos los problemas sistemáticos que produce la introducción del art. $10 \mathrm{~N}^{\circ} 11$. Así, el peligro de desfigurar los límites "de los deberes de tolerancia correlativos a los derechos de in- 
tervención sobre bienes jurídicos ajenos que resultan de la norma permisiva aplicable en situaciones de estado de necesidad agresivo" (Mañalich, 2013b, p. 720) no puede ser resuelto sin conocer el modelo conceptual sobre el cual se estructura la norma.

A continuación, considerando lo expuesto en las posiciones unitarias en torno a los efectos del estado de necesidad, analizaremos en la siguientes secciones la propuesta del profesor Cury que crea el artículo $10 N^{\circ} 11$. Ello con el objetivo de ilustrar cómo se concibe la tolerancia de la imprecisión en la regulación del artículo 10 № 11 .

\section{Propuesta del art. 10 N 11: una alternativa a la regulación alemana}

\section{¿Nuevo paradigma? Tolerancia de la imprecisión}

La regulación del estado de necesidad en el modelo jurídico alemán ha causado objeciones que exigen tomar una posición. Como se podrá observar, la sola adopción de la regulación del modelo alemán conlleva, al menos conceptualmente, que los parámetros de la justificación o exculpación dependan aparentemente de las exigencias del legislador. Una cuestión diferente es si esto implica prescindir de una argumentación que complemente la lectura de la disposición. La respuesta no es fácil, porque en la actualidad se discute cuáles deben ser las exigencias para concurrir en el estado de necesidad. Y si bien la aceptación de la regulación del Código penal alemán actual, en el ordenamiento jurídico chileno, como referente autorizado de la explicación debería simplificar el asunto, hay quienes que incluso favorables a su aceptación parecen comportarse como si estas categorías en cierta medida fueran indeseables.

Pues bien, será difícil que sin conocimiento de la plataforma conceptual sobre la cual se asienta la norma del artículo $10 N^{\circ} 11$ la interpretación se extienda más allá de un mero ejercicio retórico, incapaz de cumplir con las funciones que la dogmática le asigna en la resolución de casos concretos y que subyacen a las críticas que la posición unitaria observa en la regulación de su disposición. De ahí que seamos partidarios de abordar la problemática tanto del efecto justificante como exculpante como parte de una misma disposición ${ }^{20}$. Este procedimiento de razonamiento permite comprobar razonablemente si la disposición responde a los patrones de una norma permisiva o de inexigibilidad. La cuestión es entonces si esto puede bastar para delimitar un espacio de indeterminación que la dogmática y la jurisprudencia deberá llenar de contenido. Y se trata de una pregunta esencial, pues, planteada a propósito de casos de violencia intrafamiliar como los de Karina Sepúlveda, caracterizados por la dificultad que motiva este trabajo, una respuesta negativa implica sin más una delimitación premoral de dichos efectos.

Como se ha dicho, una interpretación más precisa sobre el estado de necesidad del art. $10 \mathrm{~N}^{\circ} 11$ supone certeza sobre dos aspectos: en primer lugar, acerca del concepto dogmático que subyace al estado de necesidad en el ordenamiento jurídico chileno, es decir, el reconocimiento de la plataforma conceptual sobre la cual se asienta la creación de la norma, y en segundo lugar, sobre cuál es la función del interprete en la delimitación de los efectos del estado de necesidad. El nexo entre estos dos aspectos, sea como elemento autónomo o propio de la naturaleza del estado de necesidad, es parte de una interpretación dogmática independiente, al menos de aquéllas cuyo resultado insiste en que el artículo $10 \mathrm{~N}^{\circ} 11$ responde a los patrones de la regulación jurídico-penal alemana. Consecuentemente, este estado de necesidad supone una corriente interpretativa, que en la práctica incide en el 20. Tarea que se pretende realizar de forma asistemática en torno a la tolerancia de la imprecisión en (Guerra, 2017, pp. 424 - 442). Sin embargo, en este trabajo desarrollamos con mayor precisión conceptual el tratamiento de la propuesta en relación con el artículo 10 N 11 del Código penal chileno. 
proceso penal. Y es precisamente esta la que dificulta la interpretación de la disposición, cuando se generan discrepancias en la valoración de la disposición como norma de permisión o exculpación. Como sea, surge la incertidumbre de si de esta forma, en el reconocimiento de un rol preponderante del intérprete se da solución a la delimitación de los efectos del estado de necesidad, porque en rigor no se está cuestionando la dualidad o la regulación del artículo $10 \mathrm{~N}^{\circ} 11$. Y si bien se trata de una imprecisión que es consecuencia inherente a esta regulación, las dificultades de delimitación son tan reiteradas que hacen necesaria una reflexión.

Cuando Cury afirmó que los efectos del estado de necesidad del art. $10 \mathrm{~N}^{\circ} 11$ era una cuestión de interpretación, en contraposición a su posición inicial ${ }^{21}$, probablemente lo hizo porque advertía que no se trataba de una mera cuestión regulativa. Pues, como indicó Acosta, en estos casos no se trata de acreditar una situación de estado de necesidad en particular sino de la imposibilidad de establecer criterios de imputación en el ordenamiento positivo. Lo que realmente tiene espacio en el estado de necesidad en el proceso penal es una discusión conceptual sobre este y sobre lo que dicha conceptualización puede decir en relación con el tipo de casos de que conoce un Juzgado de Garantía o Tribunal Oral en lo Penal. Si bien se trata de una problemática que requiere la prueba de los hechos y la subsunción de los mismos en un tipo penal permisivo o en su caso a los parámetros de la inexigibilidad ante realización de un hecho antijurídico, la materia relativa a qué regulación debe presentar el estado de necesidad se centra en solo establecer los requerimientos a los cuales debe someterse el debate y las condiciones bajo las cuales es posible una convicción razonable respecto de la concurrencia de la eximente. Por ello, en las siguientes secciones indicaremos cuáles son las razones de por qué la tolerancia de la imprecisión prevalece en el artículo 10 N 11, conforme a un criterio histórico, teleológico-objetivo y legislativo comparado.

\section{Razones históricas de la tolerancia de la imprecisión}

Desde una primera aproximación al modelo, podemos desprender que el acto en estado de necesidad puede o no constituir delito según sea exigible el sacrificio del bien amenazado o no. Además, la modalidad permite albergar tanto un efecto justificante como exculpante sin expresa distinción. Asimismo, el agente puede ejercer la acción en favor de un tercero no relacionado. También atiende a la integridad corporal, la vida, el honor, el patrimonio, sin cerrar el catálogo de derechos que pueden verse amenazados de forma taxativa al utilizar el término especialmente. Sin embargo, para llegar a esta formulación existió un proceso evolutivo, que se inicia con el Proyecto de Stooss acerca del estado de necesidad. Este ayuda no solo a la regulación del art. 34, sino también a comprender cómo fue posible llegar a concebir dos efectos en una sola regulación del estado de necesidad. En un primer momento, Stooss presentó el anteproyecto de 1893 para ser inspeccionado, antes de su publicación, por juristas de Alemania y Austria. Con esta estrategia esperó fortalecer su Proyecto antes de su presentación a la comisión de expertos en Suiza. Tiempo después, no solo se discutía sobre el anteproyecto en periódicos alemanes, sino también en los franceses e italianos. Pero su propuesta de estado de necesidad, contemplada en el art. 18 del anteproyecto, fue objeto de duras críticas de Gautier y von Liszt, porque la disposición comprendía solo un efecto exculpante (Jiménez de Asúa, 1916, pp. 197-200). Cabe advertir que el único experto consultado por Stooss fue von Liszt en el verano de 1893. Hasta la publicación del anteproyecto alemán de 1911, von Liszt debió ocuparse de las discusiones sobre Derecho penal en Suiza (Germann, 2007. pp. $180-181)$. 
Gautier consideró que la disposición se diferencia del modelo francés de la época, porque entrega una serie de reglas que no solo liberan de toda pena o la atenúan para quien ha cometido un delito por protegerse o proteger a un tercero de un peligro inminente o algunos de sus bienes, sino que exigía además que el acto punible, ante cualquiera circunstancia, fuese la única forma de enfrentar el peligro. Pues bien, el tribunal debía decidir con prudencia, considerando las circunstancias del caso, si ameritaba justificar, excusar o penar íntegramente o de forma atenuada el acto en cuestión. De ahí que Gautier indicara que le parecía dudoso subsumir la intervención en favor de un tercero en un plano exculpante. En otras palabras, la intervención en favor de un tercero solo es posible si se entrega un derecho a quien actúa en favor de este. Para Gautier, la intervención en favor de un tercero, en el campo del estado de necesidad, es válida en la medida en que el agente tenga un derecho como en la legítima defensa; de lo contrario, no existe ninguna razón que justifique la intervención en favor de un tercero. Por ello, declarar que quien actúa bajo el imperio de la necesidad no ejerce un derecho, como lo aseveró Stooss, no sería consecuente con abrir la intervención en favor de terceros no relacionados (Gautier, 1894, p. 115).

En esta línea, Stooss, en los motivos del CP suizo de 1893, declaró que solo contemplaba un efecto exculpante en el estado de necesidad. Para Stooss, si bien con frecuencia el acto realizado en estado de necesidad se considera legítimo, quien actúa en necesidad no ejecuta un derecho. Por ello, cuando un agente mata a otro, porque su vida está en peligro, no solo vulnera el amor al prójimo, sino también sus derechos. Stooss observa en el estado de necesidad solo una causa de exculpación, porque centra su argumento en situaciones en las cuales sin derecho, no existe otra forma de evitar el peligro que matando a otro ser humano. Así, el modelo de estado de necesidad fue presentado en el Proyecto de CP suizo de 1893 en su art. 18 en los siguientes términos:

"Quien comete un delito para evitar un peligro inminente e imposible de conservar de otra forma, la vida, la integridad corporal, el honor, la propiedad o cualquier otro bien que le pertenezca a él o un tercero será ejemplo de la pena o castigo de una pena atenuada, si el acto parece excusable de acuerdo a las circunstancias"22.

Por su parte, las críticas de von Liszt apuntan a que esta disposición estaría imbuida de un espíritu mezquino, porque no permite justificar aquellas situaciones donde existe el deber de actuar como ciudadano en la protección de bienes jurídicos. En este orden de ideas, no podría justificarse romper la ventana de una casa para salvar a un niño de un incendio o para dar agua a una persona desvalida en su interior u otros casos similares (Jiménez de Asúa, 1961, p. 338; von Liszt, 1893, p. 114; Stooss, 1913, p. 139). Stooss en la comisión de expertos de 1899, segundo Proyecto de CP suizo, consideró las críticas de von Liszt, señalando que la disposición del estado de necesidad tendría tanto un efecto justificante como exculpante. El autor indicó que frente a la complejidad de la realidad no es posible definir los efectos de esta

22 "Quiconque commet un délit pour préserver d'un danger imminent et impossible à détourner autrement la vie, l'intégrité corporelle, l'honneur, la propriété ou quelque autre bien appartenant à lui ou à autrui, sera, si l'acte paraît excusable d'après les circonstances, exempté de la peine ou puni d'une peine adoucie" 
disposición, debiendo atender a las circunstancias del caso concreto ${ }^{23}$. Así las cosas, Stooss presentó en el segundo Proyecto de CP suizo la formulación del estado de necesidad en el art. 35 en los siguientes términos: "Cuando un acto hubiera sido cometido para preservar de un peligro inminente e imposible de evitar de otro modo, un bien perteneciente al autor del acto o a otro, especialmente la vida, la integridad corporal, la libertad, el honor, el patrimonio, este acto no constituirá delito, si en las circunstancias en que ha sido cometido, el sacrificio del bien amenazado no podía exigirse razonablemente al autor del acto; en caso contrario, el Juez atenuará libremente la pena (art. 65)"24. La Comisión aprobó esta solución con amplia mayoría en 1899.

El Proyecto del CP suizo de 1893 transitó de una disposición que se manifestaba en favor de un efecto solo exculpante, a una disposición que contempla tanto un efecto justificante como uno exculpante en el Proyecto de 1899. En la exposición de motivos del CP suizo de 1894 podemos constatar en el art. 16 que Stooss consideró las críticas que von Liszt presentó al art. 18 del Proyecto de $1893^{25}$. Stooss manifestó que se buscó establecer un límite a la impunidad en el estado de necesidad, siendo enfático en indicar que la acción realizada en estado de necesidad no es sancionable de ser el interés salvado más importante que el sacrificado. En el ejercicio de una obligación legal o ejercicio de un derecho, es la justificación del acto evidente por sí mismo, pero en una situación de peligro de muerte, en la que una persona solo puede salvar a otra por medio del sacrificio de una vida humana, la opinión mayoritaria sugirió atender al instinto de conservación (Triebe der Selbsterhaltung) (Stooss, 1894, p. 10). Considerando estos puntos, Stooss estimó que la infinidad de casos que pueden abarcar situaciones de necesidad no permiten tener una sola disposición que contemple efectos exculpantes. El estado de necesidad requiere de una norma flexible que sea capaz de entregar una disposición amplia, satisfaciendo la multiplicidad de supuestos que comprende la institución.

En el estado de necesidad las disposiciones "más precisas, calcadas sobre las concepciones teóricas, siempre seductoras, pero en muchos casos artificiosas, no serán [siempre] las más adecuadas" (Jiménez de Asúa, 1916, p. 200 y p. 309), porque se requiere de una norma amplia que no entre en pugna con la práctica, permitiendo al juez considerar los intereses que impulsan al agente a realizar su acción, sin desconocer límites estructurales en la figura como que el mal causado no sea sustancialmente superior al que se evita ${ }^{26}$. Finalmente, debemos indicar que el CP suizo en la actualidad distingue entre un estado de necesidad justificante y exculpante1285. Por su parte, debemos indicar que lo que queda de la propuesta de Stooss, en el modelo suizo, ha sido reconducido al estado de necesidad exculpante (art. 18) ${ }^{27}$. El razonamiento de Cury, en la elaboración de la regulación del art. 10 N¹1, parece que solo tendría sustento de rescatar la plataforma conceptual del modelo suizo, con especial atención del desarrollo teórico realizado por Stooss.

23. Véase (Stooss, 1899, pp. 43-46; Jiménez de Asúa, 1961, p. 338).

24. Traducción realizada por Jiménez de Asúa, véase (Jiménez de Asúa, 1916, p. 198). Énfasis añadido.

25. Si bien la Comisión del CP suizo tenía aprobada la disposición del estado de necesidad, sin la aprobación de la oposición, von Liszt opuso duras críticas contra aquella, véase (Stooss, 1894, p. 9). En esta línea, las críticas de considerar solo un efecto exculpante en el estado de necesidad, von Liszt las presenta en Die Forderungen der Kriminalpolitik und der Vorentwurf eines schweizerischen Strafgesetzbuches, en dem Archiv für soziale Gesetzgebung und Statistik. 6. Band, $3 / 4$ Heft. Berlín 1893. Documento que se puede observar en las referencias del informe preliminar (Vorbericht) de la exposición de motivos del CP suizo de 1894, véase (Stooss, 1894, II-III; Jiménez de Asúa, 1961, p. 338, nota 99).

26. A propósito de las críticas de von Liszt al CP suizo de Stooss, Jiménez de Asúa se pregunta, considerando el deber que pueden tener los ciudadanos de intervenir en la defensa de terceros no relacionados, si en situaciones de estado de necesidad "¿sería, pues, conveniente estatuir de un modo especial -como lo hace nuestro Código de 1870- que el daño producido sea inferior al que se trata de evitar?". Ello, porque pueden darse situaciones en que "la urgencia del momento no nos permitirá hacer esta comparación", (Jiménez de Asúa, 1916, p. 200). Ante la perplejidad de la pregunta en cuestión, es necesaria una norma amplia del estado de necesidad que sea capaz de considerar una multiplicidad de supuestos.

27. Art. 18. 1 Si l'auteur commet un acte punissable pour se préserver ou préserver autrui d'un danger imminent et impossible à détourner autrement menaçant la vie, l'intégrité corporelle, la liberté, l'honneur, le patrimoine ou d'autres biens essentiels, le juge atténue la peine si le sacrifice du bien menacé pouvait être raisonnablement exigé de lui. 2 L'auteur n'agit pas de mani re coupable si le sacrifice du bien menacé ne pouvait être raisonnablement exigé de lui Lo último salvo en lo que concierne, aparentemente, a un peligro inminente y no evitable de otro modo en el art. 17 (Quiconque commet un acte punissable pour préserver d'un danger imminent et impossible à détourner autrement). 


\section{Perspectiva teleológico-objetiva de la tolerancia}

Justamente por esta característica del problema, a medio camino entre la regulación y las exigencias de imputación que concurren en el estado de necesidad justificante en el modelo jurídico alemán, es que no resulta extraño que en la dogmática chilena se produzca una significativa ampliación de la aplicación del estado de necesidad del art. $10 \mathrm{~N}^{\circ} 11$ desde la modalidad del estado de necesidad agresivo. De ahí que la interpretación tienda forzadamente a reconducir los parámetros de la interpretación a los presupuestos de un modelo jurídico comparado en nuestra actual regulación, en contraste con el carácter claramente excepcional del mismo tratándose de conclusiones más bien dogmáticas del autores que deben ayudar a los operadores del sistema jurídico-penal. Mientras en estos últimos la interpretación supone casi siempre una extrapolación de estas instituciones más o menos fundamentada, tratándose de los principios que guiarían la interpretación de las decisiones o más bien en razones ideológicas que encontrarían especio en la indeterminación semántica del concepto de peligro.

En ciertos casos no es difícil identificar el carácter justificante o incluso atípico de una conducta. En el segundo caso, por ejemplo, el ordenamiento no regula la atipicidad de acciones de las que se derivan daños no planificados. Sin embargo, el daño planificado, relacionado a un riesgo prohibido, es crucial en la identificación de una conducta criminal al ser resultado de una acción imputable. Por ello, si una enfermera pone una inyección a un paciente y la aguja se parte por la resistencia muscular de este, lo que lleva a una paralización parcial de una de sus extremidades, la enfermera no responde, porque no podía tener en consideración "la posibilidad de que [sobrevinieran] esas complicaciones (Jakobs, 1996, p. 187). El ordenamiento reclama que los agentes en sociedad respeten los intereses de terceros. Así, cuando excusa su afectación el ordenamiento es más restrictivo en los requisitos de las reglas. De ahí que si bien el ordenamiento puede excusar a los agentes para no declarar en contra de sus familiares, limita la posibilidad de beneficiarse o cometer delitos en nombre de estos.

En suma, la situación de la regulación del estado de necesidad del art. $10 \mathrm{~N}^{\circ} 11$ es indicativa de una importante transición en la compresión del estado de necesidad y de las relaciones existentes entre derecho penal material y proceso penal en el sistema jurídico penal chileno. Como lo ha destacado Greenawalt, existe un modelo de la tolerancia de la impresión sobre el cual se debe asentar la regulación del estado de necesidad e incluso las eximentes de responsabilidad. Por una parte este modelo acepta definir materialmente en términos precisos cuáles son los focos en los cuales se centra la discusión del estado de necesidad y establecer aquellos puntos sobre los cuales la prueba en el procedimiento se centrará. Este es el contexto por medio del cual se asegura no incorporar criterios de imputación que fuercen una atribución de la responsabilidad para justificar la acción realizada en estado de necesidad o la ausencia de esta.

\section{Reconocimiento de una moral intersubjetiva en la imprecisión}

Frente a la tolerancia de la imprecisión se enfrenta otra corriente para la cual es necesaria una estricta vinculación del artículo $10 \mathrm{~N}^{\circ} 11$ con el efecto justificante 0 exculpante. Ello porque es una realidad ineludible para el Derecho penal, toda vez que dichos efectos llegan a ser parte de su interpretación según la escuela que explique esta institución, con lo cual el estado de necesidad gana autonomía desde esta corriente neutralista que consagra la tolerancia de la imprecisión. Ahora bien, aunque parezca paradójico, extiende significativamente el control de la aplicación del estado de necesidad por la vía dogmática, cuya relevancia de fondo no radica en 
que la determinación de los efectos sea la antesala de una corriente filosófica, sino en que un reconocimiento ético en el derecho material pierde sus contornos. Si bien se observa, el déficit de la tolerancia de la imprecisión intenta ser compensado con alusión directa a la regulación del estado de necesidad alemán en Chile, a través de criterios de racionalidad que operan como leyes reguladoras, la aplicación de la disposición del artículo 10 N 11 se encuentra libre de estos parámetros.

Pues bien, todo parece indicar que es posible reconocer la tolerancia de la imprecisión en la disposición del artículo $10 \mathrm{~N}^{\circ}$ 11. Precisamente la problemática de su interpretación y la conciencia de sus elementos jurídico-indeterminados, son factores a través de los cuales se observa la imposibilidad de descansar solo en los presupuestos que contempla la norma. Lo que se impone no es entonces la negación de la existencia de la teoría de la diferenciación, sino más bien no predefinir los criterios y exigencias de racionalidad a través de una regulación que determine el efecto justificante o exculpante de la disposición. Así las cosas, a modo de ejemplo, en ciertos casos no es difícil identificar el carácter justificante o incluso atípico de una conducta. En el caso del carácter atípico de una conducta, el ordenamiento no regula la atipicidad de acciones de las que se derivan daños no planificados.

Sin embargo, el daño planificado, relacionado a un riesgo prohibido, es crucial en la identificación de una conducta criminal al ser resultado de una acción imputable. Por ello, si una enfermera pone una inyección a un paciente y la aguja se parte por la resistencia muscular de este, lo que lleva a una paralización parcial de una de sus extremidades, la enfermera no responde, porque no podía tener en consideración "la posibilidad de que [sobrevinieran] esas complicaciones" (Jakobs, 1996, p. 187). El ordenamiento reclama que los agentes en sociedad respeten los intereses de terceros. Así, cuando excusa su afectación el ordenamiento es más restrictivo en los requisitos de las reglas. De ahí que si bien el ordenamiento puede excusar a los agentes para no declarar en contra de sus familiares, limita la posibilidad de beneficiarse o cometer delitos en nombre de estos ${ }^{28}$.

Un caso que también debería considerarse en este contexto sería el del estado de necesidad por coacción. En este estado de necesidad el agente, en respuesta a una amenaza en contra de su persona o integrantes de su familia, infringe el ordenamiento jurídico. La conducta puede afectar a un tercero por la acción ilícita o injusta que se comete. El estado de necesidad por coacción generalmente es definido como una excusa, porque el razonamiento del agente se encuentra en una posición injusta en la elección. La regulación del estado de necesidad no establece dicha preferencia como justificada, porque la acción viola intereses de mayor entidad que pueden afectar incluso la vida de terceros.

De este modo, sería preferible que el agente no cediera ante la amenaza que lo lleva a delinquir. Sin embargo, qué pasaría en el caso de que alguien amenace al agente con matar a cinco estudiantes de una escuela si no hurta una bicicleta. Muchos determinarían que esta acción se encontraría justificada, porque efectivamente causaría un mal menor al que se pretende evitar (Greenawalt, 1986, pp. 103-104). En el modelo jurídico-chileno, la defensa aplicable sería dogmáticamente un estado de

28. Así, conforme al art. 17 del CP, son encubridores los que con conocimiento de la perpetración de un crimen o de un simple delito o de los actos ejecutados para llevarlo a cabo, sin haber tenido participación en él como autores ni como cómplices, intervienen, con posterioridad a su ejecución [...] [estando] exentos de las penas impuestas a los encubridores los que lo sean de su cónyuge, de su conviviente civil, o de sus parientes por consanguinidad o afinidad en toda la línea recta y en la colateral hasta el segundo grado, de sus padres o hijos, con la sola excepción de los que se hallaren comprendidos en el número $1^{\circ}$ de este artículo, que dispone: aprovechándose por sí mismos o facilitando a los delincuentes medios para que se aprovechen de los efectos de crimen o simple delito. Por otra parte, respecto de la facultad de no declarar por motivos personales, el art. 302 del CPP preceptúa en su inciso primero que no estarán obligados a declarar el cónyuge o el conviviente del imputado, sus ascendientes o descendientes, sus parientes colaterales hasta el segundo grado de consanguinidad o afinidad, su pupilo o su guardador, su adoptante o adoptado. 
necesidad coactivo en el art. $10 N^{\circ} 11$. Sin embargo, en el modelo anglosajón sería posiblemente aplicable la excusa de duress, porque la acción responde solo a la amenaza del actuar doloso de un tercero (Greenawalt, 1986, pp. 100).

En nuestro medio, la acción del agente de hurtar la bicicleta quizás sería considerada como justificada; sin embargo, también podría estimarse solo un efecto exculpante, únicamente por el hecho de que las condiciones de la amenaza tienen un propósito antijurídico por vinculación a circunstancias externas a la norma de conducta. Podemos observar que existen valoraciones sociales múltiples en torno a los efectos del estado de necesidad para la resolución de casos. Así, frente a la multiplicidad de opiniones en la materia, no es posible establecer un criterio de moral social unitario en una regulación del estado de necesidad. La regulación del estado de necesidad requiere de cierta tolerancia de la imprecisión. Establecer la denominación de justificante o exculpante en una regulación del estado de necesidad impone un criterio moral unitario. Una regulación por medio de este tipo de fijaciones inserta expresiones calificativas que no pueden predeterminarse. La regulación del estado de necesidad debe ser neutra (Greenawalt, 1986, pp. 106). Por ello, el estado de necesidad del art. $10 \mathrm{~N}^{\circ} 11$ deja de lado todo subtítulo, con independencia de que nuestra dogmática y jurisprudencia desarrollen categorías.

Uno podría pensar que el costo de una formulación como la del art. $10 \mathrm{~N}^{\circ} 11$ es aceptar un vacío e imprecisión en la interpretación de la norma, que incluso podría incidir en la interpretación de otras defensas. En la legítima defensa nadie discute su efecto justificante, a pesar de no determinar ese efecto. El art. $10 N^{\circ} 11$, a diferencia del CP alemán, tolera la imprecisión de efectos, pues no pretende fijar una consecuencia determinada, y sus términos admiten la posibilidad de contemplar tanto un efecto justificante como exculpante en una sola regulación. Semejante modelo dualista muestra el reconocimiento de una moral intersubjetiva propia de una sociedad democrática (Nagel, 1991, passim; Larmore, 1987, passim; Barry,1995, passim; Jones, 2003, p. 97).

Esta posición del liberalismo ha llegado a tratar la tolerancia como un principio filosófico fundamental. Se estima que la tolerancia juegue un papel esencial en la concepción política de justicia que se pretenda construir en sociedad. En esta línea, Rawls afirmó que la tolerancia es una de las grandes virtudes políticas que una sociedad debe promover entre sus ciudadanos (Rawls, 1993, pp. 122-123, 157 y 194-195)29. Tolerancia que estamos de acuerdo en sustentar en la regulación nacional del estado de necesidad; sin embargo, esta posición ya no es aceptable al resolver el caso particular. Así, la dogmática debe entregar una perspectiva de análisis que oriente en la aplicación de la norma al caso. Esto implica aceptar una estructura de argumentación racional que, ciertamente, diferirá en sus resultados de considerar la existencia de prohibición deóntica.

La neutralidad puede ser exigida como una virtud a los ciudadanos y a las instituciones públicas. Sin embargo, nos parece que la tolerancia demanda del dogmático jurídico-penal definir cuáles son las razones del porqué una determinada perspectiva de análisis es incorrecta y cuáles son las razones para proceder en los términos de otra. Así pues, una posición neutral en el plano dogmático nos parece desacertada. El neutralismo solo reconoce una razón de primer orden: no rechazar ninguna posición (Mackled-García, 2003, p. 320)30. De este modo, la tolerancia de la imprecisión cobra vida en la coexistencia de diversas posiciones deónticas o de su ausencia al analizar 29. Sin embargo, existe una contraposición a la excesiva valoración que realiza Rawls de la tolerancia en su política liberal en (Tan, 2000, passim; Kymlicka, 1995, pp. 152-153).

30. En contra de esta interpretación, (Jones, 2003, pp. 100-110). Asimismo, respecto de la distinción de las razones de primer y segundo orden en plano normativo, véase (Raz, 1975, passim). 
un caso. En esta línea, no es posible desconocer un plano analógico a la moral, que en el campo del estado de necesidad incide en la forma de observar la realidad. Independientemente de las diferencias que puedan existir entre la neutralidad y la tolerancia, ambas parecen ser relevantes en una política liberal.

La dogmática no puede ser neutral respecto del núcleo fundamental de la dignidad humana, sobre todo si consideramos que ciertas acciones en supuestos del llamado estado de necesidad defensivo podrían justificar el sacrificio de otros sujetos inocentes, sin límites u otras consideraciones. En la dogmática penal existe el riesgo de comprender políticas que denoten un menor precio del núcleo esencial de la dignidad humana. En esta línea, las pretensiones de neutralidad en la dogmática nos parecen admisibles solo en la medida en que avance desde una concepción permisible que respete los principios de un Derecho penal liberal. Pero esta concepción de la permisibilidad debe circunscribirse a una posición deóntica. De este modo, la permisibilidad no respondería a una apelación de la conciencia donde ciertas prácticas serían tolerables o intolerables por el solo hecho de apelar a ciertos principios.

Ahora bien, nos parece que la pregunta más relevante es si esta tolerancia que presenta la disposición del art. $10 \mathrm{~N}^{\circ} 11$ se puede observar como una ventaja. Parece que desde un plano normativo sería adecuado, porque permite a la dogmática dar un tratamiento amplio a la determinación de los efectos en el estado de necesidad. Sin embargo, todo tipo de tolerancia en esta defensa sería inadecuada desde un punto deóntico-dogmático, porque solo respondería a la necesidad de subsumir todo caso de peligro a la norma generando inseguridad jurídica. Suponiendo en un plano normativo que es deseable y posible una neutralidad axiológica en la elaboración de las normas, nos parece sumamente complejo derivar de una norma una tolerancia moral neutra desde la cual se desprendan principios de justicia. No creemos que exista semejante norma. Podríamos sostener que la tolerancia moral es neutra entre diferentes concepciones de bien o mal. La carga del juicio que recae en diferentes dogmáticos no es unívoca en situaciones de extrema necesidad propias al aborto, la eutanasia, entre otras materias, independientemente de la existencia de ciertos consensos. Por ello, la dificultad de determinar la razonabilidad de estas posturas podría encaminarnos a reconocer que la tolerancia sería la mejor política para resolver estos casos en el plano de la dogmática ${ }^{31}$.

\section{Conclusiones}

Las refutaciones de las posiciones unitarias a la formulación del artículo 10 N 11 siguen vigentes en el sistema jurídico-penal chileno. Cualquier justificación de la tolerancia de la imprecisión supera tales refutaciones en el estado de necesidad. Son superables desde un análisis teleológico-objetivo que denote la plataforma conceptual sobre la cual se asienta la construcción de la disposición. Puede así afirmarse que, en la línea de argumentación expuesta, la tolerancia de la imprecisión es el reconocimiento del orden moral intersubjetivo del artículo $10 N^{\circ} 11$, en razón de una corriente neutralista que pretende no ser tajante en la distinción o los parámetros de justificación o exculpación en el estado de necesidad. Dicha interpretación puede llevarse a cabo respetando una lectura histórica, teleológica objetiva y legislativo comparada, que sitúa la interpretación del artículo $10 \mathrm{~N}^{\circ} 11$ en el contexto de un Derecho penal liberal democrático. Modelo de Derecho penal que reconoce la convivencia de diferentes criterios axiológicos. La tolerancia de la imprecisión permite aceptar la indeterminación de los efectos del estado de necesidad por antonomasia.

31. Respecto de esta ambigüedad o extrema vaguedad en la carga del juicio (burden of judgment) en el liberalismo político de Rawls, véase (Churchill, 2003, pp. 73-74). 
Sin embargo, no desconoce que es una tarea dogmática y jurisprudencial desarrollar criterios de orientación para los operadores del sistema.

La tolerancia de la imprecisión da cita a una corriente neutralista. Esta rechaza seguir la regulación que presenta el modelo jurídico alemán en el estado de necesidad. Al estar enraizado en el modelo jurídico alemán requisitos rígidos que fuerzan aceptar la preconcepción del legislador en materia de justificación y exculpación. Las reglas de la tolerancia de la imprecisión incluyen reconocer la tradición desde la cual se realiza la valoración del efecto del estado de necesidad. También en esta arista se pone en evidencia cómo el paradigma filosófico que se adopte evidencia la complejidad de la problemática. Sobre todo bajo los moldes de comedimiento morales absolutistas que subyacen en a la posición de Cury y Stooss en la construcción de un particular estado de necesidad, es decir, el artículo $10 \mathrm{~N}^{\circ} 11$. Y, por supuesto, en el efecto comunicativo del mismo en la exención de responsabilidad penal. Según tal planteamiento, la tolerancia de la imprecisión opera como correlato de una tarea hermenéutica ajena a una posición axiológicamente neutra.

\section{Bibliografía}

Acosta Sánchez, J. D. (2013). "Artículo 10 N $^{\circ}{ }^{\circ}$ y $11^{\circ}$ del Código Penal. Algunos criterios de delimitación", en Van Weezel (ed.). Humanizar y renovar el Derecho penal. Estudios en memoria de Enrique Cury. 702. Santiago, LegalPublishing.

Barry, B. (1995). Justice and Impartiality. Reino Unido, Oxford, Claredon.

Bullemore, V. y Mackinnon, J. (2007). Curso de Derecho Penal, Teoría del delito. Tomo II, (2a ed). Santiago, LexisNexis.

Canaris, C.W. (1995). Función, estructura y falsación de las teorías jurídicas. Madrid, Civitas.

Churchill, R. P. (2003). "Neutrality and the virtue of toleration", en: Castiglione / Mckinnon (eds.), Tolerantion, Neutrality and Democracy (Stuttgart, Springer-Science+Business Media, B.V.) 65-186.

Coca Vila, I. (2011). “Entre la responsabilidad y la solidaridad. El estado de necesidad defensivo", en InDret, Revista para el análisis del Derecho. 1- 40. Barcelona, Universidad Pompeu Fabra.

Cousiño Mac Iver, L. (1979b). Derecho penal chileno. Parte general. Tomo II. Santiago, Editorial Jurídica de Chile.

Couso Salas, J. (2006): Fundamentos del Derecho penal de culpabilidad. Historia, teoría y metodología. Valencia, Tirant lo Blanch.

Cury, E, Derecho Penal. Parte General, (7ª ed). Santiago, Ediciones Universidad Católica de Chile.

Etcheberry, A. (1998a). Derecho Penal. Tomo I (3a ed). Santiago, Editorial Jurídica de Chile.

Etcheberry, A. (1998b). Derecho Penal. Tomo // (3 ed). Santiago, Editorial Jurídica de chile. 
Fontecilla Riquelme, R. (1964): "Los problemas jurídicos de las causas supralegales en materia penal", en Anales de la Facultad de Ciencias Jurídicas y Sociales, vol. 3, $N^{\circ}$ 3. Santiago, Universidad de Chile.

FreudenthaL, B. (2006). Culpabilidad y reproche en el Derecho penal (trad. J.L. Guzmán Dalbora) Buenos Aires, Editorial B de f.

Fuentes, D. (2009). La ponderación de los males en el estado de necesidad. Santiago, LegalPublishing.

García Soto, M. P. (1999). El estado de necesidad en materia penal. Santiago, Editorial Jurídica ConoSur.

Gautier, A. (1894). Deux Projets. La réforme pénale en France et en Suisse. Berne, Imprimerie Karl Staempfli \& Cie)

Germann, U. (2007). "Zwischen nation building und Internationalismus - die schweizerische Strafrechtsreform in inter- und transnationaler Perspektive", en Kesper-Bierman / Petra Overath (Hrsg.), Die Internationalisierung von Strafrechtswissenschaft und Kriminalpolitik (1870 - 1930). Deutschland im Vergleich. Berlín, Berliner Wissenschafts-Verlag GmbH.

Greenawalt, K. (1986). "Distinguishing Justifications from Excuses", en Revista Law \& Contemporary Problems, vol. 49, №3, p. 89- 108. Special Editor for this Symposium.

Guerra Espinosa, R. (2018). "Sentido y límites de la inevitabilidad en el estado de necesidad" en Revista lus Et Praxis, 24(3), 67-108. Chile, Universidad de Talca.

Guerra Espinosa, R. (2017). "Ambivalencia en el principio del interés preponderante" en Revista de Derecho. N.49, 187-215. Chile, Pontificia Universidad Católica de Valparaíso.

Guerra Espinosa, R. (2014). "Estado de necesidad exculpante: A propósito de actos de defensa por efectos del maltrato a partir de un caso emblemático" en Revista de derecho y ciencias penales: Revista de Derecho. 33-80. Chile, Universidad San Sebastián.

Guerra Espinosa, R. (2017). "Principio de no contradicción en el estado de necesidad" en Revista de Derecho, vol.30, N.2, 367-389. Chile, Universidad de Valdicia.

Guzmán Dalbora, J.L. (2010). Cultura y delito, Bogotá, Editorial Temis.

Hernández Basualto, H. (2011b). "Comentario al art. 10 N 11 del Código Penal”, en: Couso Salas / Hernández Basualto (dirs.), Código Penal Comentado. Parte General. Doctrina y jurisprudencia. Santiago, AbeledoPerrot-LegalPublishing.

Jakobs, G. (1996) La imputación objetiva en Derecho penal. Madrid, Cuadernos Civitas.

Jiménez de Asúa, L. (1916). El Derecho penal del porvenir. La unificación del Derecho penal en Suiza. Madrid, Hijos de Reus). 
Jones, P. (2003). "Toleration and neutrality: Compatible ideals?", en: Castiglione / Mckinnon (eds.), Tolerantion, Neutrality and Democracy. Stuttgart, Springer-Science Business Media, B.V.

Kymlicka, W. (1995). Multicultural Citizenship. Oxford, Clarendon.

Larmore, C. (1987). Patterns of Moral Complexity. Cambridge, Cambridge University Press.

Mackled-García, S. (2003). "Toleration and Neutrality: Incompatible Ideals?", en Castiglione / Mckinnon (edit.), Toleration, Neutrality and Democracy (Dordrecht, Springer Science Business Media).

Maurach, R. (1994). Derecho penal: Parte general, actualizado por Heinz Zipf (trad. Jorge Bofill Genzsch y Enrique Aimone Fomtecci Gibson, supervisada por Edgardo A. Donna. Buenos Aires, Astrea.

Nagel, T. (1991). Equality and Partiality. Oxford, Oxford University Press.

Novoa Monreal, E. (2005a) Curso de Derecho Penal chileno. Parte General. Tomo I (3ª ed). Santiago, Editorial Jurídica de Chile.

Ortiz Muñoz, P. (1933). Nociones generales de Derecho penal. Santiago, Editorial Nascimento.

Ossandón Widow, M.M. (2012). "Aborto y justificación", Revista Chilena de Derecho, vol. 39, N². 325-369. Santiago, Pontificia Universidad Católica de Chile.

Politoff Lifschitz, S. (2003). Lecciones de Derecho Penal. Parte General. Tomo I (2ª ed). Santiago, Editorial Jurídica de Chile).

Rawls, J. (1993). Political Liberalism. New York, Columbia University Press.

Raz, J. (1975). Practical Reason and Norms. London, Hutchinson.

Roxin, C. (1997). Derecho penal. Parte general. Tomo l. Fundamentos de la estructura de la teoría del delito (trad. D.M. Luzón Peña et al., (2ª ed). Madrid, Civitas.

Santibáñez Torres, M. E. y Vargas Pinto, T. (2011). "Reflexiones en torno a las modificaciones para sancionar el femicidio y otras reformas relacionadas", en Revista Chilena de Derecho, vol. 38, N 1.193- 207. Chile, Pontificia Universidad Católica de Chile.

Sepúlveda Sánchez, I. (2012). "Algunas consideraciones sobre el estado de necesidad contemplado en el artículo $10 \mathrm{~N}^{\circ} 11$ del Código Penal y su reconocimiento por la jurisprudencia" en Revista Jurídica del Ministerio Público, № 53. Chile, Fiscalía Nacional de la Intitución.

Silva Sánchez, J. M. (1982). "Sobre el estado de necesidad en derecho penal español" en Anuario de Derecho Penal y Ciencias Penales, Tomo 35, Fascículo n 3. 663- 691. España, Universidad Autónoma de Barcelona. 
Stooss, C. (1894). Schweizerisches Strafgesetzbuch. Motive zu dem Vorentwurf im Auftrage des schweizerischen Bundesrates. Bern, Buchdruckerei Karl \& Stämpfli \& Cie.

Tan, Kok-Chor. (2000). Toleration, Diversity and Global Justice. Pennsylvania, Pennsylvania University Press.

Van Weezel, A. (2008). Error y mero desconocimiento en Derecho penal. Santiago, LegalPublishing.

Vargas, T. (2013b). Manual de derecho penal práctico: Teoría del delito con casos ( $3^{\mathrm{a}}$ ed). Santiago, LegalPublishing.

Vial del Río, V. M. (1969). La no exigibilidad de otra conducta como causa de exclusión de la culpabilidad. Santiago, Editorial Jurídica de Chile.

Von Liszt, F. (1893). "Die Forderungen der Kriminalpolitik und der Vorentwurf eines schweizerischen Strafgesetzbuchs", en von Liszt, F. Strafrechliche Aufsätze und Vorträge. Band 2. 1892: Bis 1904. Berlín, Walter de Gruyter.

Wilenmann, J. (2014a). “El fundamento del estado de necesidad justificante en el derecho penal chileno. Al mismo tiempo, introducción al problema de la dogmática del estado de necesidad en Chile", en Revista de Derecho, vol. 27, №3. 213- 244. Chile, Universidad de Valdia. 